Wallens, R. M. (1990). Flying Made My Arms Ache. Self-Publishing Association, Upton-onSevern.

KEY WORDS

I. Aircraft lighting. 2. Safety. 3. Approach and landing. 4. Human factors.

\title{
Position by Observation of a Single Body
}

\section{Roy Williams}

1. INTRODUCTION. Matti Ranta ${ }^{1}$ in his paper published in this Journal in May 1990 described a method of computing an observed position from the observation of a single body around the time of culmination. His equations would suggest, however, that the computation is valid at any time that the heavenly body is visible to the observer.

Let us start with Ranta's equation ( 10 ) in his paper which we here will label as equation ( 1 ).

We will use the symbols :

$\alpha$ to denote altitude

$\phi$ to denote latitude $\left(-\frac{1}{2} \pi \leqslant \phi \leqslant \frac{1}{2} \pi\right.$ : North positive)

$\theta$ to denote longitude ( $0 \leqslant \theta<2 \pi$ : East positive)

$\chi$ to denote declination

$\lambda$ to denote $2 \pi-G H A$

$Z$ to denote the azimuth

$V$ to denote the velocity of the observer

$\gamma$ to denote the course made good by the observer

$\Omega$ to denote $d \lambda / d t$.

In this notation the equation is:

$$
\begin{aligned}
\frac{d \alpha}{d t}=\left[V \cos \gamma-\cos (\lambda-\theta) \frac{d \chi}{d t}\right] & \cos Z \\
& +\left[V \sin \gamma+\sin (\lambda-\theta) \sin \phi \frac{d \chi}{d t}-\Omega \cos \phi\right] \sin Z .
\end{aligned}
$$

2. GENERALIZATION OF THE METHOD OFRANTA ${ }^{1}$. It would seem that at any time other than the time of culmination we can just as well take a series of observations of the altitude, $\alpha$, of heavenly body and, after fitting a least squares function approximation, $\alpha(t)$, through the data points, we would differentiate to find $\alpha^{\prime}\left(t_{0}\right)$ at a time, $t_{0}$, which we would choose for finding an observed position. Substituting this value of $\alpha^{\prime}\left(t_{0}\right)$ in equation ( 1$)$ we could use this equation to find our first and subsequent approximations to $Z_{n}$ combined then with equations (2) and (3) below to form an iterative scheme for computing $(\lambda-\theta)$ and $\phi$ at time $t_{0}$.

$$
\begin{gathered}
\sin (\lambda-\theta)_{n}=\frac{\sin Z_{n} \cos \alpha}{\cos \chi} \\
\cos \phi_{n}=\frac{\sin \alpha-\sin \phi_{n-1} \sin \chi}{\cos \chi \cos (\lambda-\theta)_{n}} .
\end{gathered}
$$


Let us consider first that the observer is stationary, so that $V=0$ in equation ( $\mathrm{I}$ ). The equation then becomes:

$$
\frac{d \alpha}{d t}=\left[\sin (\lambda-\theta) \sin \phi \frac{d \chi}{d t}-\cos \phi \frac{d \lambda}{d t}\right] \sin Z-\left[\cos (\lambda-\theta) \frac{d \chi}{d t}\right] \cos Z .
$$

If we express equation (4) in the form

we find

$$
R \sin (Z-k)=\frac{d \alpha}{d t}
$$

$$
Z=k+\sin ^{-1}\left[\frac{1}{R} \frac{d \alpha}{d t}\right]
$$

where

$$
\tan k=\frac{\cos (\lambda-\theta) d \chi / d t}{\sin (\lambda-\theta) \sin \phi d \chi / d t-\cos \phi d \lambda / d t}
$$

and

$$
R^{2}=\left[\sin (\lambda-\theta) \sin \phi \frac{d \chi}{d t}-\cos \phi \frac{d \lambda}{d t}\right]^{2}+\left[\cos (\lambda-\theta) \frac{d \chi}{d t}\right]^{2}
$$

the procedure would then be to take a series of observations $\alpha_{1}, \alpha_{2}, \ldots, \alpha_{n}$ at times $t_{1}$, $t_{2}, \ldots, t_{n}$, respectively, such that $t_{1}<t_{0}<t_{n}$, to fit a function approximation $\alpha(t)$, from which we can determine $\alpha\left(t_{0}\right)$, and differentiate to find $\alpha^{\prime}\left(t_{0}\right)$.

Using the values of $\alpha\left(t_{0}\right)$ and $\alpha^{\prime}\left(t_{0}\right)$ so found, we can compute the angle $Z$ as above and then the $L H A(=\lambda-\theta)$ from

$$
\sin (\lambda-\theta)=\frac{\sin Z \cos \alpha\left(t_{0}\right)}{\cos \chi}
$$

Ranta $^{1}$ uses a least squares quadratic polynomial approximation to determine $\alpha(t)$ and, while this will work well at the time of culmination, it is not accurate enough in the general case. For a stationary observer on the surface of the Earth the altitude, $\alpha$, of a heavenly body is given by the equation:

$$
\sin \alpha=\sin \phi \sin \chi+\cos \phi \cos \chi \cos (\lambda-\theta) \text {. }
$$

If we write $y=\sin \alpha$ we should, therefore, be able to approximate to this with a sinusoidal function of the form

$$
y=A \sin x+B \cos x+C
$$

where $x=\lambda-\theta$. The period of the trigonometric functions is the length of the apparent day (the period elapsing between two successive transits of the observer's meridian by the heavenly body). If the body is observed at times $\left\{t_{\mathrm{i}}\right\}$ with corresponding altitudes $\left\{\alpha_{i}\right\}$ then we fit $y$ to this data in the least squares sense so that:

$$
S=\sum\left\{y_{\mathrm{i}}-\left(A \cos x_{\mathrm{i}}+B \sin x_{\mathrm{i}}+C\right)\right\}^{2}
$$

is a minimum.

If we find the partial derivatives of $S$ with respect to $A, B$ and $C$ then these are the 'normal' equations and furnish a set of linear equations (5) from which to determine the $A, B, C$ :

$$
\left[\begin{array}{ccc}
\sum \cos ^{2} x_{i} & \sum \cos x_{1} \sin x_{i} & \sum \cos x_{i} \\
\sum \cos x_{i} \sin x_{i} & \sum \sin ^{2} x_{i} & \sum \sin x_{i} \\
\sum \cos x_{1} & \sum \sin x_{i} & \sum{ }_{I}
\end{array}\right]\left[\begin{array}{c}
A \\
B \\
C
\end{array}\right]=\left[\begin{array}{c}
\sum y_{i} \cos x_{i} \\
\sum y_{i} \sin x_{i} \\
\sum y_{i}
\end{array}\right] .
$$

There are certain circumstances where the matrix defining the system (5) is singular or nearly so. This occurs, for instance, at the time of culmination and again when the hour 
angle $\lambda-\theta(=x)$ and the altitude $\alpha\left(=\sin ^{-1} y\right)$ are both close to $45^{\circ}$. In such cases we will perhaps overcome this by using the least squares orthogonal polynomial approximations as described by Forsythe ${ }^{2}$.

3. EXPERIMENTAL RESULTS. In the absence of observed data, we can test the computational procedure by using the values of the altitude of the Sun given in Davis's Tables ${ }^{3}$. These tables are intended to give the values of the true altitude of the Sun (correct to the nearest one minute of arc) at intervals of eight minutes, but the tables are very old and some of the entries are not, in fact, correct to the nearest minute. We have corrected any entry from Davis that we found to be wrong and we have then applied the trigonometric least squares approximation to this corrected data.

TABle I. Sun altitudes v. Latitude and hour angle

\begin{tabular}{ccccccc}
\hline & \multicolumn{6}{c}{ Hour angle $(\lambda)$} \\
\cline { 2 - 6 } Latitude & $349^{\circ}$ & $347^{\circ}$ & $345^{\circ}$ & $343^{\circ}$ & $341^{\circ}$ & $339^{\circ}$ \\
\hline $30^{\circ}$ & $77^{\circ} 56^{\prime}$ & $76^{\circ} 27^{\prime}$ & $14^{\circ} 53^{\prime}$ & $73^{\circ} 17^{\prime}$ & $71^{\circ} 39^{\prime}$ & $69^{\circ} 59^{\prime}$ \\
$35^{\circ}$ & $74^{\circ} 39^{\prime}$ & $73^{\circ} 31^{\prime}$ & $72^{\circ} 16^{\prime}$ & $70^{\circ} 57^{\prime}$ & $69^{\circ} 34^{\prime}$ & $68^{\circ} \circ 9^{\prime}$ \\
$40^{\circ}$ & $70^{\circ} 38^{\prime}$ & $69^{\circ} 46^{\prime}$ & $68^{\circ} 48^{\prime}$ & $67^{\circ} 45^{\prime}$ & $66^{\circ} 38^{\prime}$ & $65^{\circ} 26^{\prime}$ \\
$45^{\circ}$ & $66^{\circ} 15^{\prime}$ & $66^{\circ} 35^{\prime}$ & $64^{\circ} 50^{\prime}$ & $64^{\circ} \circ 0^{\prime}$ & $63^{\circ} \circ 6^{\prime}$ & $62^{\circ} \circ 8^{\prime}$ \\
$50^{\circ}$ & $61^{\circ} 40^{\prime}$ & $61^{\circ} \circ 9^{\prime}$ & $60^{\circ} 34^{\prime}$ & $59^{\circ} 55^{\prime}$ & $59^{\circ} 11^{\prime}$ & $58^{\circ} 24^{\prime}$ \\
$55^{\circ}$ & $56^{\circ} 59^{\prime}$ & $5^{\circ} 35^{\prime}$ & $5^{\circ} \circ 6^{\prime}$ & $55^{\circ} 36^{\prime}$ & $55^{\circ} \circ 1^{\prime}$ & $54^{\circ} 24^{\prime}$ \\
\hline
\end{tabular}

On the bridge of an ocean-going cargo ship in good observing conditions one would normally expect the readings from the sextant to give altitudes at better accuracy than one minute. The common form of the sextant used by seagoing navigators is usually read to $\triangle \cdot I$ of a minute and, although one might not expect the altitudes always to be accurate to that level, it might not be unreasonable to expect accuracy to 0.2 of a minute. Using the spherical cosine formula we have therefore compiled a second table of altitudes correct to 0.25 of a minute in order to test the application of the Forsythe polynomials to our least squares approximation. The Forsythe polynomials did not give such good results when the data was expressed to the level of accuracy of one minute but gave acceptable results at the level of accuracy of 0.25 minutes.

For the purposes of testing the procedure of computing the position of an observer we have sited the observer on the Greenwich Meridian (longitude $\circ^{\circ}$ ) and at latitudes ranging from $30^{\circ}$ to $55^{\circ}$ North.

Example. June $101990-1100$ GMT. Declination $23^{\circ} 0117^{\circ} \mathrm{N}$. Rate of change of declination $0.001597^{\circ}$ /hour. Hour Angle $345^{\circ} 9^{\circ} 9^{\prime}$. Rate of change of Hour Angle $-14.998^{\circ} /$ hour. Longitude $0^{\circ}$.

The picture presented by the data of Table $\mathrm{I}$ is the 'static' picture - the declination of the Sun is kept fixed. Allowance for the effect upon the rate of change of altitude by the rate of change of declination is made by the added term:

$$
\left(\frac{\sin \phi \cos \chi-\cos \phi \sin \chi \cos (\lambda-\theta)}{\cos \alpha}\right)\left(\frac{d \chi}{d t}\right) .
$$

The results from the computation using the above data from Table 1 are shown below in Table 2.

Table 3 corrects the altitudes of the Sun given in Table 2 to 0.25 of a minute.

Table 4 shows the results from using the Forsythe polynomials on the data in Table 3 . 
TABLE 2. TABLE I RESUltS MODIFIED for RATE OF CHANGE OF DECLINATION

\begin{tabular}{|c|c|c|c|c|c|c|}
\hline Latitude & $\begin{array}{l}\text { True } \\
\text { altitude }\end{array}$ & $\begin{array}{l}\text { Computed } \\
\text { altitude }\end{array}$ & $\begin{array}{l}\text { True } \\
\text { rate }\end{array}$ & $\begin{array}{c}\text { Calculated } \\
\text { rate }\end{array}$ & $\begin{array}{l}\text { Hour } \\
\text { angle }\end{array}$ & Longitude \\
\hline $30^{\circ}$ & $75^{\circ} 0167$ & 75.0180 & I 1.8401 & I I 8377 & $14^{\circ} 49^{\circ} 8^{\prime}$ & $0^{\circ} 0.3^{\prime} \mathrm{E}$ \\
\hline $35^{\circ}$ & $72 \cdot 3749$ & $72 \cdot 3724$ & 9.5632 & 9.5662 & $14^{\circ} 50.5^{\prime}$ & $0^{\circ} 0.4^{\prime} \mathrm{W}$ \\
\hline $40^{\circ}$ & 68.8854 & 68.8858 & 7.5174 & 7.5194 & $14^{\circ} 50^{\circ} 3^{\prime}$ & $0^{\circ} 0.2^{\prime} \mathrm{W}$ \\
\hline $45^{\circ}$ & $64 \cdot 8996$ & $64 \cdot 897$ I & $5.893^{\circ}$ & 5.8964 & $14^{\circ} 50.7^{\prime}$ & $0^{\circ} 0.6^{\prime} \mathrm{W}$ \\
\hline $50^{\circ}$ & 60.6192 & 60.6192 & 4.6322 & 4.6256 & $14^{\circ} 4^{\circ} 7^{\prime}$ & $0^{\circ} I^{\prime} 4^{\prime} \mathrm{E}$ \\
\hline $55^{\circ}$ & 56.1562 & $56 \cdot 1577$ & 3.6416 & 3.6575 & $14^{\circ} 54^{\circ} 0^{\prime}$ & $0^{\circ} 3.9^{\prime} \mathrm{W}$ \\
\hline
\end{tabular}

Table 3. Corrected Sun altitudes

\begin{tabular}{|c|c|c|c|c|c|c|}
\hline \multirow[b]{2}{*}{ Latitude } & \multicolumn{6}{|c|}{ Hour angle $(\lambda)$} \\
\hline & $349^{\circ}$ & $347^{\circ}$ & $345^{\circ}$ & $343^{\circ}$ & $34^{1^{\circ}}$ & $339^{\circ}$ \\
\hline $30^{\circ}$ & $77^{\circ} 56 \frac{1}{4}$ & $76^{\circ} 26 \frac{1}{2}^{\prime}$ & $74^{\circ} 53^{\frac{1}{4}}$ & $73^{\circ} 17^{\prime}$ & $71^{\circ} 39^{\prime}$ & $69^{\circ} 59 \frac{1}{4}$ \\
\hline $35^{\circ}$ & $74^{\circ} 39 \frac{1}{4}^{\prime}$ & $73^{\circ} 30 \frac{1}{2}$ & $72^{\circ} 16 \frac{1}{4}$ & $70^{\circ} 57^{\prime}$ & $69^{\circ} 34^{\frac{1}{4}}$ & $68^{\circ} \circ 8 \frac{1}{2}$ \\
\hline $40^{\circ}$ & $70^{\circ} 38^{\prime}$ & $69^{\circ} 46^{\prime}$ & $68^{\circ} 48 \frac{1}{4}^{\prime}$ & $67^{\circ} 45 \frac{1}{4}$ & $66^{\circ} 37 \frac{3}{4}^{\prime}$ & $65^{\circ} 26 \frac{1}{2}$ \\
\hline $45^{\circ}$ & $66^{\circ}$ I $5^{\prime}$ & $65^{\circ} 35^{\frac{1}{4}}$ & $64^{\circ} 50^{\prime}$ & $64^{\circ} 00 \frac{1}{4}^{\prime}$ & $63^{\circ} 06^{\prime}$ & $62^{\circ} \circ 8^{\prime}$ \\
\hline $50^{\circ}$ & $61^{\circ} 40 \frac{1}{4}$ & $61^{\circ} \circ 9 \frac{1}{4}$ & $60^{\circ} 34^{\prime}$ & $59^{\circ} 54^{\frac{3}{4}}$ & $59^{\circ} \times 1 \frac{1}{4}$ & $5^{\circ} 24 \frac{1}{2}$ \\
\hline $55^{\circ}$ & $56^{\circ} 5^{8} \frac{1^{\prime}}{2}$ & $56^{\circ} 34^{\frac{1}{2}}$ & $56^{\circ} \circ 7^{\prime}$ & $55^{\circ} 35^{\frac{3}{4}}$ & $55^{\circ} \circ \mathrm{I}^{\prime}{ }^{\prime}$ & $54^{\circ} 24^{\prime}$ \\
\hline
\end{tabular}

TABLE 4. Results fRom Forsythe POlyNomials

\begin{tabular}{|c|c|c|c|c|c|c|}
\hline Latitude & $\begin{array}{c}\text { True } \\
\text { altitude }\end{array}$ & $\begin{array}{l}\text { Computed } \\
\text { altitude }\end{array}$ & $\begin{array}{l}\text { True } \\
\text { rate }\end{array}$ & $\begin{array}{l}\text { Computed } \\
\text { rate }\end{array}$ & $\begin{array}{l}\text { Hour } \\
\text { angle }\end{array}$ & Longitude \\
\hline $30^{\circ}$ & 75.0167 & 75.0165 & $11 \cdot 8401$ & II $\cdot 8280$ & $14^{\circ} 49^{\circ} 2^{\prime}$ & $0^{\circ} 0.9^{\prime} \mathrm{E}$ \\
\hline $35^{\circ}$ & $72 \cdot 3749$ & 72.3750 & 9.5632 & 9.5605 & $14^{\circ} 49^{-8^{\prime}}$ & $0^{\circ} 0.3^{\prime} \mathrm{E}$ \\
\hline $40^{\circ}$ & $68 \cdot 8854$ & 68.8869 & 7.5174 & 7.5042 & $14^{\circ} 4^{8 \cdot 4^{\prime}}$ & $0^{\circ} I^{\prime} 7^{\prime} E$ \\
\hline $45^{\circ}$ & 64.8996 & 64.8997 & 5.8930 & 5.9012 & $14^{\circ} 5^{1} \cdot 4^{\prime}$ & $0^{\circ} I^{\prime} 3^{\prime} W$ \\
\hline $50^{\circ}$ & $60 \cdot 6192$ & 60.6 I 88 & 4.6322 & $4^{6} 147$ & $14^{\circ} 46 \cdot 6^{\prime}$ & $0^{\circ} 3.5^{\prime} \mathrm{E}$ \\
\hline $55^{\circ}$ & $56 \cdot 1562$ & $56 \cdot 155^{6}$ & $3 \cdot 6416$ & 3.6370 & $14^{\circ} 49^{\circ} 0^{\prime}$ & $0^{\circ} I^{\prime} I^{\prime} E$ \\
\hline
\end{tabular}

6. CONCLUSION. In good observing conditions at sea, the kind of conditions which would be necessary in any case for taking astronomical observations, the results above should be achievable. Indeed, a good observer would expect altitudes to be of greater accuracy than one minute of arc. Most micrometer sextants are read to 0.1 of a minute of arc and all computations assume this accuracy. As they stand, most of the results for the longitude found above would be very acceptable to an observer on an ocean passage.

We have not included an example in which allowance is made for the moving observer. Sufficient to say that this should not significantly alter the method of computation. The speed $V$ in equation ( $\mathrm{r}$ ) is the speed of the observer in knots divided by 60 . The speed should be known to the nearest knot. If, after the computation is complete, the speed made good from the last observed position differs from the estimated speed by as much as a half a knot then a second approximation of the observed position should be computed using this new estimate of the speed.

James $\mathrm{N}$. Wilson ${ }^{4}$ also described a method of finding the position by observation of a single body at the time of culmination. His method uses a graphical solution but this 
would be difficult to apply in the general case since the rate of change of altitude is required to an accuracy of two decimal places and this would be difficult to attain graphically.

\section{REFEREN CES}

1 Ranta, M. (1991). Position fixing in a fast moving ship by culmination of a celestial body. This Journal, 43, 276 .

2 Forsythe, G. E. (1957). Generation and use of orthogonal polynomials for data-fitting with a digital computer. Journal of Industrial Applied Mathematics, 5, 2.

${ }_{3}$ Davis, P. L. H. (1918). Altitude - Azimuth Tables. HMSO.

4 Wilson, J. N. (1985). Position from observation of a single body. Navigation (Journal of the American Institute of Navigation), 32.

I. Astro. 2. Marine navigation.

\section{On the Two-Body Running Fix}

\section{Kenneth Gibson}

If an observer can determine the altitudes of two bodies simultaneously, he can place himself at one of two positions on the Earth's surface. This fact has been the basis for several proposed methods for obtaining a fix without reference to a DR or assumed position, the latest of which is due to Chiesa and Chiesa. ${ }^{1}$ Chiesa and Chiesa's procedure is straightforward and elegant if the sights are simultaneous, or if the sights are not simultaneous but the observer is stationary, but there seems to be a need for a simple method of extending it to cover a running fix. Chiesa and Chiesa themselves proposed transferring the geographical position of the first body before calculating the fix. Williams ${ }^{2}$ questioned the accuracy of transferring the geographical position and, instead, solved the problem by transferring the first position circle pointwise; his method is sufficiently complex to require a computer, as he himself notes. Metcalf ${ }^{3}$ presented exact equations for transferring the geographical position of a body and its associated circles of altitude ; however, application of Metcalf's equations assumes prior knowledge of the observer's position. Brown's approach ${ }^{4}$ was to move the observer's DR on to the first position circle before using it to advance the geographical position of the first body. Based on his experience with Chiesa and Chiesa's method, Pepperday ${ }^{5}$ argued that knowledge of a good DR position can be put to better use as part of a conventional running fix using position lines deduced by the Marcq St Hilaire or the modified Sumner method. Apparently, all users and advocates of Chiesa and Chiesa's method consider that the calculations involved are complex enough to require a computer. ${ }^{1-6}$

Here, I present a simple solution for the two-body running fix without DR, which is accurate whenever the usual simplifying assumptions of the Marcq St. Hilaire method apply: namely, that the position lines are locally straight (equivalently, the azimuths are effectively independent of position) and the surface of the Earth is locally flat. The solution lends itself to an easy graphical construction, which will be described first. Subsequently, I show how to obtain the same solution with a hand calculator, and indicate how to find the position using Ageton's method of sight reduction and a timesight table or formula. 